\title{
Los openings, antesala del relato de ficción en televisión: identidad y marca
}

\section{Opening sequences, the entrance hall on television fiction: identity building and brand}

\author{
Magro-Vela, S., Puebla-Martínez, B. y Baraybar Fernández, A. ${ }^{1}$ \\ Recibido: 27-03-2020 - Aceptado: 10-08-2020 \\ https://doi.org/10.26441/RC19.2-2020-A10.1
}

RESUMEN: Los openings han sufrido un proceso de transformación hasta convertirse en parte integrante e integradora del relato ficcional. Se presenta el estudio de las cabeceras de Isabel, Víctor Ros y El Ministerio del tiempo, de Javier Olivares, llevado a cabo desde 4 ejes: análisis de aspectos formales, narrativos, tipográficos y sonoros. Mediante los rasgos comunes y disímiles compartidos con los títulos de crédito cinematográficos se pretende comprobar la relación que guardan con el proceso de construcción de identidad y marca del producto audiovisual como unidad independiente de su creador.

Palabras Clave: opening; series de televisión; análisis narrativo; diseño gráfico; identidad.

ABSTRACT: Opening sequences has been suffered from a transformation process until becoming an integral and integrating part of fictional story. The present text collects a study of the opening of Isabel, Víctor Ros and El Ministerio del tiempo, created by Javier Olivares. A research developed from four main points of work, analysis of formal, narrative, typographic and sound aspects. Through common and dissimilar traits shared with credit titles, it is about proving the relationship with the building process of identity and brand of the audiovisual product as an independent unit from its creator.

Key words: opening; television shows; narrative analysis; graphic design; identity.

\footnotetext{
${ }^{1}$ Silvia Magro-Vela es Máster en Cine, Televisión y Medios Interactivos, así como Licenciada en Comunicación Audiovisual y Profesora Visitante de Diseño Gráfico Audiovisual y Diseño Gráfico y Dirección de Arte en la Facultad de Ciencias de la Comunicación de la Universidad Rey Juan Carlos. silvia.magro@urjc.es, https://orcid.org/00000002-0695-8813

Belén Puebla-Martínez es Doctora en Comunicación Audiovisual y Profesora Ayudante Doctora de Métodos de investigación en comunicación en la Facultad de Ciencias de la Comunicación de la Universidad Rey Juan Carlos. belen.puebla@urjc.es, https://orcid.org/0000-0002-1481-4238

Antonio Baraybar Fernández es Doctor en Ciencias de la Información por la Universidad Complutense de Madrid y Profesor Titular de Estrategia y Comercialización Audiovisual y Empresa de Publicidad y Gestión de Cuentas en la Facultad de Ciencias de la Comunicación de la Universidad Rey Juan Carlos. antonio.baraybar@urjc.es, http:// orcid.org/0000-0002-5474-5214
} 


\section{Introducción}

Los títulos de crédito son el preludio de cualquier obra audiovisual independientemente de su naturaleza y características. Con el paso de las décadas su función ha dejado de ser meramente informativa y se han ido incorporando otras como la narrativa o, incluso, la identitaria.

Estos fragmentos pueden funcionar como prólogo, pero también como epílogo del relato en cuestión, en palabras de Labaig (2007: 2) "[...] se encuentran al principio y al final de la obra, enmarcándola [...]". Es en esa labor de apertura y cierre cuando sucede la transición entre lo real y lo inventado, el telón traspasado por el espectador para adentrarse suavemente en el mundo narrativo. En definitiva, estos elementos denominados por Bort (2012) "partículas narrativas" han alcanzado entidad propia convirtiéndose en muchos casos en piezas maestras poseedoras de un innegable valor para con la obra a la que sirven de antesala.

Como objetivo principal, se pretende determinar cómo los openings de las series de ficción televisiva contribuyen a la creación de identidad y construcción de marca del producto audiovisual como unidad independiente del creador. Se lleva a cabo este objetivo mediante una suma de elementos que se subdividen en los siguientes objetivos específicos: observar otros componentes de las secuencias introductorias para establecer sus características y ver cómo se relacionan entre sí; analizar los elementos narrativos que aparecen en dichos fragmentos y su interconexión con aquéllos que construyen el relato principal; comprobar el uso de los elementos textuales que aparecen en los openings; y estudiar la tipología de la banda sonora que complementa los elementos visuales de las cabeceras.

\section{Marco teórico}

La relevancia de los títulos de crédito cinematográficos ha sido reconocida y actualmente es indudable. Estos fragmentos son el precedente a la dedicación, tanto económica como creativa, presente en nuestros días en productos audiovisuales de ficción como las series de televisión y sus secuencias introductorias, las cabeceras; productos que se han convertido, como destaca Cascajosa (2016: 24), en parte nuclear de la cultura contemporánea.

Debido a la complejidad en la delimitación de la taxonomía referente a los fragmentos narrativos que configuran la arquitectura de las series (previously, teaser, pre-opening, pre-ending o ending) y su diferenciación de las características que mantienen con las cabeceras en el resto de formatos televisivos (Hervás, 2002: 38-39), la propuesta de Bort parece ser la más ajustada para la definición de los openings:

Partícula extradiegética estructural de una serie de televisión que, a través de múltiples posibilidades formales y de integración en el relato, se presenta, de modo reiterativo, en la apertura de cada uno de sus episodios, con el objetivo de informar al espectador acerca del título de la serie y, con frecuencia, del creador, reparto protagonista y otros créditos limitados de especial relevancia (Bort, 2012: 247).

El cine mantiene en cierto modo el aura que rodea a las obras únicas, pensado para que el espectador se sienta inmerso en una atmósfera cercana a la del ritual. Por el contrario, en el caso de la televisión lineal el contenido audiovisual está integrado dentro de una programación de flujo continuo. La fragmentación narrativa inherente al relato televisivo tradicional se contrapone a la posición temporal única que mantiene la narración en el cine (Williams, 2016: 59), pues la emisión puntual de este último se enfrenta a la semanal de las series televisivas. En esta línea, Cuadrado (2017: 222) alude a la cualidad de "producto de continuidad" que debe mantener el interés de la audiencia entre la emisión de un capítulo y otro. 
Sin embargo, con la incursión de las plataformas de contenido digital — derivada entre otras cosas, del desarrollo y la convergencia tecnológica - los hábitos de consumo se están viendo modificados. De esta forma, como define Poniewozik (2015), la "streaming $t v$ "- donde plataformas del estilo de HBO o Netflix proveen al espectador de contenido narrativo sin intermitencias- ha derivado en el consumo continuado o binge-watching.

A pesar del aumento de producciones internacionales con amplia envergadura y calado entre la audiencia, el estudio de los openings televisivos no presenta un dilatado recorrido académico. En este sentido, y refiriéndose a investigaciones que sobrepasen los límites concernientes al diseño gráfico y se acerquen a la narrativa, Cuadrado (2017: 217-18) apunta que "si ha sido muy escasa la atención que se les ha prestado en el medio cinematográfico, menos aún lo ha sido en el televisivo".

Por tanto, los openings detentan una posición capital respecto de la serie a la que introducen, al contribuir a la construcción de la "seña de identidad que diferencia a unos productos de otros" (Zallo, 1992: 12). Así pues, su diseño y realización se hacen vitales en la búsqueda de la aceptación y el éxito por parte de la audiencia.

Una de las cuestiones que tanto los títulos de crédito como los openings comparten es su funcionalidad. Las cuatro funciones que recoge Gamonal (2013) son "narrativa" porque aportan claves sobre la obra, "persuasiva" en su pretensión de atraer al espectador, "informativa" al ofrecer los datos del contenido audiovisual e "identificativa" en su objetivo de crear una imagen de marca.

La creación de marca es el resultado de un proceso complejo global y el opening puede resultar una herramienta de gran relevancia en su desarrollo, siempre que atienda a criterios de coherencia con el relato que presenta. Pues, entre otros aspectos, permite la diferenciación entre la abundante oferta disponible, en ocasiones de contenidos similares, al ser un atributo específico creado con la intención de significar los valores propios del relato al que preceden (Baraybar, 2006: 155).

Cualquier marca posee una dimensión evidentemente intangible y, como nos recuerda el publicista David Ogilvy (1983: 14), "una marca reside por encima de todo en la mente de las personas que acceden a ella a través de uno o de varios puntos de contacto". El profesor David Aaker (1996) incide en las asociaciones que el propio creador de marca debe generar y mantener, convirtiendo los valores y emociones transmitidos en un compromiso entre el creador y su público. La marca es, por tanto, "un referente entre la organización, los distintos grupos de interés y, en general, la sociedad" (Baraybar y Luque, 2018: 438).

Acercando estos conceptos generales al objeto de estudio, las series replican la idea a la que alude Costa (2005: 54) al referirse a las cadenas de televisión, ya que éstas poseen una personalidad que las diferencia entre ellas; de esta forma, "las audiencias engullen programas, pero perciben, caracterizan y evalúan" consiguiendo así "colocarlas en una especie de memoria clasificatoria, un archivo mental". La configuración de este "archivo mental" implica la necesidad de proyectar una imagen conceptualizada no como una sucesión de mensajes aislados, sino como un conjunto de elementos compactos que aportan un valor intangible diferencial que ayuda a modelar la imagen de la serie. Una idea que Costa (2012: 21) resume en: "La marca es el todo y las partes".

Se pueden encontrar ciertas similitudes entre las cabeceras de las series de ficción y la novela victoriana del siglo XIX, cuando el suspense llegaba a su punto culminante y la acción proseguía tras una puerta cerrada. Un buen opening debe, además de transmitir información, contribuir a ese constructo mental que es la marca y potenciar mediante la persuasión el interés del espectador por adentrarse en la historia seriada e incrementar su lealtad. 


\section{Metodología}

Para llevar a cabo el estudio propuesto, la muestra está formada por las series: Isabel (TVE, 20122014), Victor Ros (TVE, 2015-2016) y El Ministerio del tiempo (TVE, 2016-2017), todas ellas emitidas en el prime time de TVE y han sido creadas por Javier Olivares. Como se puede ver en la tabla 1, las tres series que sirven de epicentro para esta investigación contaron con gran aceptación por parte de los espectadores durante la emisión de su primera temporada, momento en el que se genera la relación con el espectador ${ }^{2}$.

Tabla 1. Audiencia de Isabel, Victor Ros y El Ministerio del Tiempo en su primera temporada.

\begin{tabular}{|l|c|c|c|}
\multicolumn{1}{|c|}{ Serie } & $\begin{array}{c}\text { Media de } \\
\text { espectadores }\end{array}$ & $\begin{array}{c}\text { Audiencia } \\
\text { media }\end{array}$ & $\begin{array}{c}\text { Audiencia media } \\
\text { de la cadena }\end{array}$ \\
\hline Isabel & 4.035 .000 & $19,9 \%$ & $10,7 \%$ \\
\hline Víctor Ros & 2.345 .000 & $11,7 \%$ & $10 \%$ \\
\hline EI Ministerio del Tiempo & 2.476 .000 & $12 \%$ & $10 \%$ \\
\hline
\end{tabular}

Fuente: Kantar Media. Elaboración propia.

Para poder alcanzar los objetivos planteados, se afronta el análisis de los openings desde distintos ámbitos y se utiliza como base metodológica las técnicas cualitativas. Se lleva a cabo un análisis del texto audiovisual siguiendo el modelo de Casetti y Di Chio (2017) y se trabaja en cuatro fases diferenciadas pero complementarias entre ellas, como muestran a continuación las tablas 2, 3, 4 y 5. Asimismo, se utiliza como punto de partida el modelo propuesto por Pérez Rufí y Jódar Marín (2018) para el estudio de una secuencia y se personalizan las variables para conseguir llegar a los objetivos propuestos.

Tabla 2. Variables del análisis formal: donde se estudia la composición de la imagen.

\begin{tabular}{|c|c|c|}
\hline $\begin{array}{l}\text { Tipología del plano } \\
\text { (Millerson, 1991; Inceer, 2007; Solana } \\
\text { y Boneu, 2007) }\end{array}$ & \multicolumn{2}{|l|}{$\begin{array}{l}\text {-Plano General (PG) } \\
\text {-Plano Entero (PE) } \\
\text {-Plano Americano (PA) } \\
\text {-Plano Medio (PM) } \\
\text {-Primer Plano (PP) } \\
\text {-Plano Detalle (PD) }\end{array}$} \\
\hline \multirow{2}{*}{$\begin{array}{l}\text { Naturaleza de la imagen } \\
\text { (Pérez Rufí y Jódar Marín, 2018) }\end{array}$} & Tipología de imagen & $\begin{array}{l}\text {-Imagen en movimiento } \\
\text {-Imagen fija } \\
\text {-Imagen generada digitalmente }\end{array}$ \\
\hline & Origen de la imagen & $\begin{array}{l}\text {-Contenido original creado } \\
\text {-Contenido de archivo } \\
\text {-Contenido creado de imitación de archivo }\end{array}$ \\
\hline & \multicolumn{2}{|l|}{ Duración del plano } \\
\hline $\begin{array}{l}\text { Ritmo } \\
\text { (Salt, 2006; Baxter, 2014; Castillo, } \\
\text { 2016) }\end{array}$ & Movimientos de cámara & $\begin{array}{l}\text {-Panorámica } \\
\text {-Panorámica digital } \\
\text {-Zoom } \\
\text {-Zoom digital } \\
\text {-Travelling } \\
\text {-Travelling digital }\end{array}$ \\
\hline
\end{tabular}

Fuente: elaboración propia.

\footnotetext{
${ }^{2}$ No se tiene en cuenta la serie Malaka (TVE, 2019), creada también por Javier Olivares, ya que su emisión no superó la media de audiencia de la cadena.
} 
Tabla 3. Variables del análisis narrativo de los elementos esenciales del relato.

\begin{tabular}{|c|c|c|c|c|}
\hline \multirow{9}{*}{$\begin{array}{l}\text { Opening } \\
\text { narrativo }\end{array}$} & \multirow{3}{*}{$\begin{array}{l}\text { Personajes } \\
\text { (Casetti y } \\
\text { Di Chio, } \\
\text { 2017; Bort, } \\
\text { 2012) }\end{array}$} & \multirow[t]{2}{*}{$\begin{array}{l}\text { Personaje } \\
\text { como rol }\end{array}$} & $\begin{array}{l}\text { Peso del } \\
\text { personaje }\end{array}$ & $\begin{array}{l}\text {-Protagonista } \\
\text {-Secundario } \\
\text {-Colaboración especial } \\
\text {-Personaje episódico }\end{array}$ \\
\hline & & & $\begin{array}{l}\text { Posición respecto } \\
\text { a otros personajes }\end{array}$ & $\begin{array}{l}\text {-Espacio propio } \\
\text {-Espacio compartido }\end{array}$ \\
\hline & & $\begin{array}{l}\text { Personaje } \\
\text { como actante }\end{array}$ & $\begin{array}{l}\text { Identificador actor/ } \\
\text { actante }\end{array}$ & $\begin{array}{l}\text {-Separación total actor/actante y rótulos del actor } \\
\text {-Presencia actor/actante pero sin vinculación con } \\
\text { rótulos } \\
\text {-Presencia actor/actante y rótulos vinculados } \\
\text {-Presencia de actor sin referencia al actante, con } \\
\text { rótulos vinculados e incluso mirando a cámara }\end{array}$ \\
\hline & \multirow{3}{*}{ Ambientes } & $\begin{array}{l}\text { Naturaleza de } \\
\text { los espacios }\end{array}$ & \multicolumn{2}{|l|}{$\begin{array}{l}\text {-Espacio exterior } \\
\text {-Espacio interior }\end{array}$} \\
\hline & & $\begin{array}{l}\text { Tipos de } \\
\text { espacio }\end{array}$ & \multicolumn{2}{|c|}{$\begin{array}{l}\text {-Espacio abstracto } \\
\text {-Espacio representativo } \\
\text {-Espacio real } \\
\text {-Espacio propio }\end{array}$} \\
\hline & & $\begin{array}{l}\text { Relación } \\
\text { espacios } \\
\text { opening y serie }\end{array}$ & \multicolumn{2}{|c|}{$\begin{array}{l}\text {-Sin relación } \\
\text {-Con relación } \\
\text {-Sin relación conocida }\end{array}$} \\
\hline & \multirow{3}{*}{$\begin{array}{l}\text { Tiempo } \\
\text { (Genette, } \\
1997)\end{array}$} & Pasado & \multicolumn{2}{|c|}{$\begin{array}{l}\text {-Prehistoria } \\
\text {-Edad Antigua y Edad Media } \\
\text {-Historia Contemporánea } \\
\text {-Siglo XXI } \\
\text {-Pasado reciente } \\
\text {-Pasado indeterminado }\end{array}$} \\
\hline & & Presente & \multicolumn{2}{|c|}{$\begin{array}{l}\text {-Presente } \\
\text {-Presente indeterminado }\end{array}$} \\
\hline & & Futuro & \multicolumn{2}{|c|}{$\begin{array}{l}\text {-Futuro cercano } \\
\text {-Futuro indeterminado }\end{array}$} \\
\hline
\end{tabular}

Fuente: elaboración propia.

Tabla 4. Variables del análisis de elementos textuales que intervienen en la creación del título.

\begin{tabular}{|c|c|}
\hline Categoría tipográfica (Brown, 1992) & $\begin{array}{l}\text {-Caracteres con remate } \\
\text {-Caracteres de palo seco } \\
\text {-Caracteres rotulados } \\
\text {-Caracteres decorativos }\end{array}$ \\
\hline Tamaño del texto & -Porcentaje que ocupa en pantalla \\
\hline Posición del texto & $\begin{array}{l}\text {-Posición cuadrante superior izquierdo } \\
\text {-Posición cuadrante superior derecho } \\
\text {-Posición cuadrante inferior izquierdo } \\
\text {-Posición cuadrante inferior derecho } \\
\text {-Posición centrada }\end{array}$ \\
\hline Relleno de la fuente & $\begin{array}{l}\text {-Color sólido } \\
\text {-Textura } \\
\text {-Transparencia }\end{array}$ \\
\hline Borde & $\begin{array}{l}\text {-Sin borde } \\
\text {-Con borde }\end{array}$ \\
\hline Sombra & $\begin{array}{l}\text {-Sin sombra } \\
\text {-Con sombra }\end{array}$ \\
\hline \multicolumn{2}{|c|}{ Duración del texto (Casetti y Di Chio, 2017; Pérez Rufí y Jódar Marín, 2018) } \\
\hline $\begin{array}{l}\text { Integración del texto en el discurso (Casetti y } \\
\text { Di Chio, 2017; Pérez Rufí y Jódar Marín, 2018) }\end{array}$ & $\begin{array}{l}\text {-Texto diegético } \\
\text {-Texto extradiegético }\end{array}$ \\
\hline
\end{tabular}

Fuente: elaboración propia. 
Tabla 5. Variables del análisis de la banda sonora para observar la interrelación con los elementos visuales.

\begin{tabular}{|c|c|c|c|c|}
\hline \multirow{4}{*}{$\begin{array}{l}\text { Tipo de elemento sonoro } \\
\text { (Casetti y Di Chio, 2017; } \\
\text { Matamala y Orero, 2011) }\end{array}$} & \multicolumn{4}{|l|}{$\begin{array}{l}\text {-Voz } \\
\text {-Ruido }\end{array}$} \\
\hline & \multirow{3}{*}{-Música } & \multirow{3}{*}{$\begin{array}{l}\text {-Composición } \\
\text {-Autoría }\end{array}$} & \multicolumn{2}{|l|}{$\begin{array}{l}\text {-Lírica } \\
\text {-Instrumental }\end{array}$} \\
\hline & & & $\begin{array}{l}\text {-Independiente } \\
\text { a la serie }\end{array}$ & $\begin{array}{l}\text {-Original } \\
\text {-Versionada }\end{array}$ \\
\hline & & & -Dependiente & -Compuesta para la serie \\
\hline \multirow{2}{*}{$\begin{array}{l}\text { Naturaleza de la fuente } \\
\text { sonora } \\
\text { (Casetti y Di Chio, 2017; } \\
\text { Bordwell y Thompson, } \\
\text { 1995) }\end{array}$} & \multirow{2}{*}{\multicolumn{2}{|c|}{$\begin{array}{l}\text {-Diegético } \\
\text {-Offscreen }\end{array}$}} & -Onscreen & $\begin{array}{l}\text {-Interior } \\
\text {-Exterior }\end{array}$ \\
\hline & & & $\begin{array}{l}\text {-Interior } \\
\text {-Exterior }\end{array}$ & \\
\hline
\end{tabular}

Fuente: elaboración propia.

\section{Análisis de resultados}

Se procede a la exposición de los datos obtenidos del análisis siguiendo la estructura compuesta por los cuatro ejes de estudio: formal, narrativo, tipográfico y de sonido.

\subsection{Análisis formal}

En primer lugar, se ha de prestar atención a las duraciones totales de los tres openings. Isabel cuenta con la cabecera más corta de las tres — 23"- , seguida de Víctor Ros con 45" y, la más extensa, la de El Ministerio del Tiempo con 1'03". Estas duraciones adquieren similitudes con los tiempos propios manejados en publicidad (20", 30", 45" o 1'), acercando estos fragmentos a la idea de promoción del contenido audiovisual. No obstante, ninguna rebasa los dos minutos, extensión mencionada por Picarelli (2013).

Sin embargo, hay otro aspecto que determina las características del opening en cuanto a 'tempos', la duración de los planos. Una vez diseccionados los tres genéricos y aplicado el Average Shot Length se ha obtenido la duración media de éstos para cada cabecera. Así mismo siguiendo la propuesta de Salt (2006: 390) en la que se refiere a la "[...] expression variation in cutting rate, depending on the nature of the scene", al poner en relación la duración media con la total del opening se observa cómo la intención de cada serie se hace visible a través del ritmo.

Isabel — con una duración media de dos segundos por plano - presenta un ritmo más lento que Victor Ros - un segundo por plano - que muestra una cabecera enérgica y dinámica. En esta última se refleja la velocidad con la que se suceden los acontecimientos en la propia serie y plantea la tensión que destilan la acción y el suspense de los crímenes a resolver. En Isabel el ritmo también conecta con la trama, pero en el extremo opuesto, ya que se narra el lento recorrido de la protagonista hasta llegar al trono con la utilización de planos más duraderos e imágenes ralentizadas.

Tanto en Isabel como en Victor Ros, el ritmo se establece de manera externa, es decir a través del montaje o edición y no de la construcción interna de la imagen, técnica de la que sí se sirve $E l$ Ministerio del tiempo. Esta serie propone un ritmo construido desde dentro mediante planos largos — duración media de siete segundos por plano-y la integración de planos secuencia. Por esta razón presenta el plano de mayor duración de las tres series, que da comienzo a la cabecera y que abarca dieciocho segundos. No se hace complicado deducir entonces que el opening que presenta más planos es Víctor Ros, con más de treinta, frente a las otras dos que no alcanzan la mitad de esta 
cifra. Esto confirma la idea de Salt (2006) de que los números nos aportan datos para comprender su funcionamiento.

La secuencia de El Ministerio del tiempo, imagen 1, hace que el espectador se conduzca sin apenas apreciarlo entre los planos gracias al movimiento interno y de la cámara. Como recoge Castillo (2016) la expresividad narrativa existente detrás de los movimientos de cámara ayuda a aportar significado a las imágenes. En este opening las siluetas recorren el espacio acompañadas de la cámara que cumple una función descriptiva y caminan entre épocas, lugares y acontecimientos como lo hacen los protagonistas en cada capítulo.

Imagen 1. Fotogramas del opening de El Ministerio del tiempo.
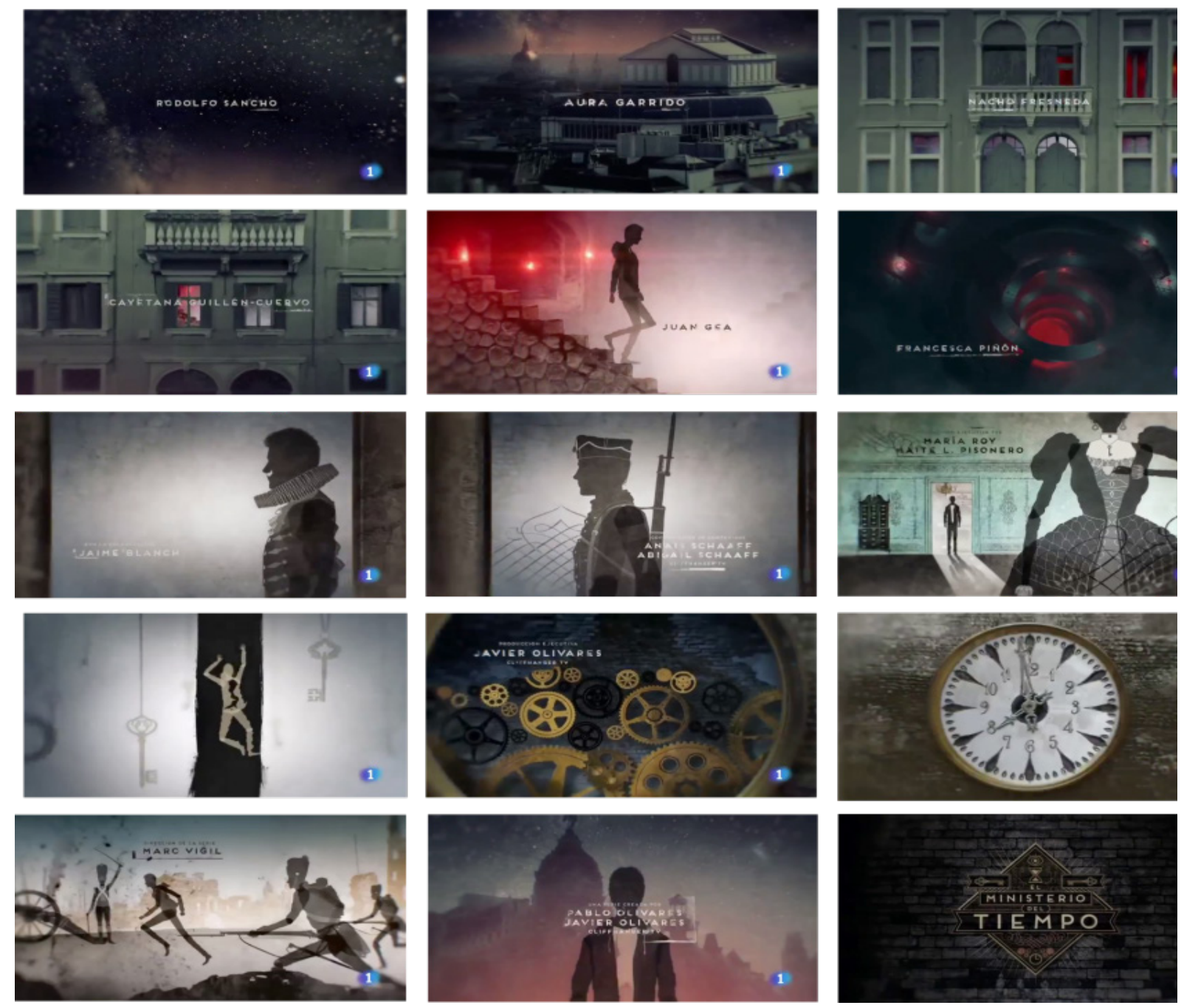

Fuente: RTVE. Elaboración propia.

Otra muestra de esta expresividad se ve en Isabel con el zoom in de inicio en el que la cámara se adentra en un bosque. De esta manera se pretende acercar la mirada del espectador a la historia que se va a contar seguidamente. También son efectivas las panorámicas que siguen el vuelo del águila y que toman la posición de la propia audiencia en su papel de acompañamiento de la historia.

Diferente es el uso que hace Víctor Ros de los movimientos de cámara que cumplen una función meramente estética y no expresiva. Abundan los zoom in y los zoom out pero que funcionan como una herramienta más para aportar sensación de dinamismo y velocidad a la cabecera. 
La elección de los tamaños de plano en los tres fragmentos resulta significativa. Continuando con las ideas aportadas por Millerson (1991) y Castillo (2016) sobre el poder persuasivo que posee la cámara y el significado que transmite una imagen en función de su tamaño, se ha estudiado la composición de los planos. A través del equilibrio de los planos utilizados en el genérico de Isabel cinco de ellos son planos detalle y los otros seis son amplios - se puede dilucidar la doble vertiente inherente a la narrativa del relato. Por un lado, se presenta la visión histórica del trascurrir de los hechos desde un punto de vista neutro e impersonal, mientras que, por otro, se muestra la parte más interna e íntima de la vida de la protagonista como se puede ver en la imagen 2.

Imagen 2. Fotogramas del opening de Isabel
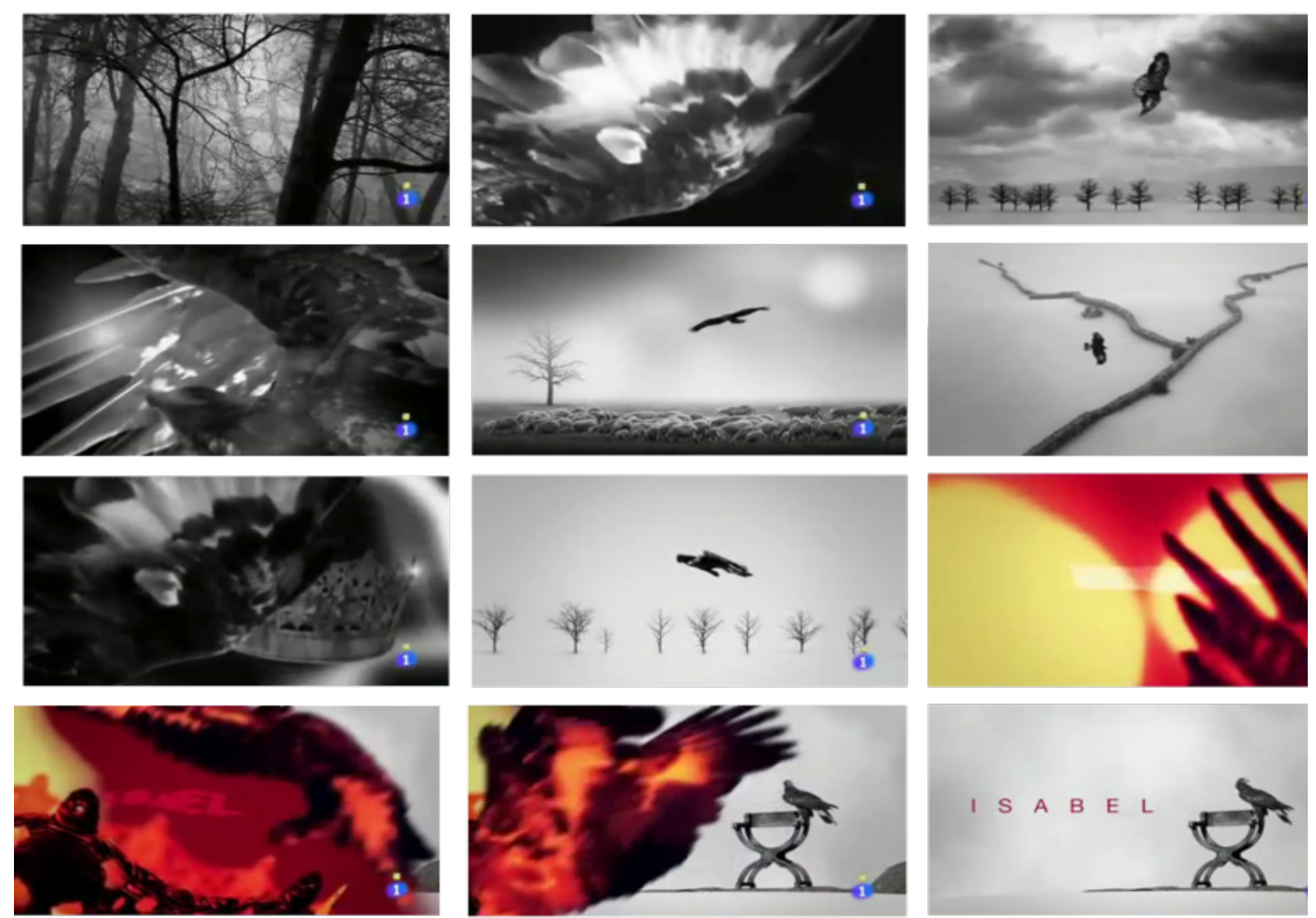

Fuente: RTVE. Elaboración propia.

Algo que también sucede en El Ministerio del tiempo, donde priman los planos amplios que denotan la pretensión de contar una historia sin focalizar en los aspectos más personales de los protagonistas para sustentarla. Obviamente, en todo relato aparecen las relaciones personales y el mundo interior, pero en este caso se encargan de hilvanar a largo plazo la conexión entre las tramas episódicas y no de conformar el núcleo narrativo.

Otros rasgos a destacar en este análisis formal, serían la naturaleza y el origen de la imagen. En los tres casos se dan imágenes originales creadas para la producción que introducen; lo cual implica una relación total respecto a la construcción de las referencias con el contenido principal.

Si bien todas tienen esta variable común, prestando atención a las categorías utilizadas en línea con las propuestas por Inceer (2007) y Solana y Boneu (2007), cada una le ha dado solución de forma disímil. Isabel con el uso de imagen en movimiento, Víctor Ros mediante fotografía o imagen fija que recrea imágenes de archivo de la época, y El Ministerio del tiempo por generación digital. 
Para concluir este análisis formal, resulta relevante hacer alusión al color y al uso inteligente que se le ha dado. En Isabel se ha optado por el blanco y negro, que representa la dicotomía entre el bien y el mal, una idea presente en la vida de la reina Isabel donde la felicidad y los logros se ven empañados en ocasiones por el sacrificio y el sufrimiento. A su vez, el uso de imágenes en blanco y negro transmite la esencia del personaje, su elegancia y su austeridad.

En el lado opuesto están, Víctor Ros y El Ministerio del tiempo con el uso del color. La primera se sirve del color para ubicar la historia en la época en que se desarrolla con fotos viradas a sepia. También introduce el rojo, brillante y saturado que alude a la sangre de los crímenes que investiga el protagonista en cada capítulo. La segunda serie busca destacar lo que se oculta detrás, lo que permanece escondido a simple vista. Mediante colores más brillantes y saturados se centra la atención del espectador en el interior del edificio a través de las ventanas o en el fondo de la escalera de caracol donde se ubican las puertas del tiempo. También se ilumina una silueta tras una puerta o una escena que queda encerrada tras el muro, justo al final de la pieza. Como se podrá ver a partir de ahora, algunos rasgos del análisis narrativo contienen ligazón con el precedente estudio formal y con los análisis tipográficos y de sonido posteriores. Esta cualidad hace compleja la separación estanca de algunos aspectos y variables.

\section{2. Análisis narrativo}

Primeramente, se convierte en imprescindible la clasificación de los tres opening atendiendo a su narratividad. Para entender qué se ha establecido como opening narrativo, se tomará como referencia lo que no lo es; es decir, cuando una cabecera cumple la función de opening como logo. Bort (2012: 249) define estas partículas y alude a que "[...] toda la pieza se concibe y construye para representar la aparición del título y solo en algunos casos queda tiempo para la figura del created by como rótulo inmediato". Por lo tanto, el opening como logo sería aquel fragmento que no tiene relación con el relato más allá de la de informar del nombre de la serie y servir como marca puramente comercial en consonancia con el uso que se da a la imagen de marca de cualquier producto mercantil.

Una vez concluida esta disgregación, se puede afirmar que los tres genéricos pertenecen a los clasificados como narrativos. Bien es cierto, que a pesar de compartir esta tipología no son los tres iguales. Cabe destacar el caso de Isabel donde se hace un uso connotativo de las imágenes frente a Victor Ros y El Ministerio del tiempo, conformadas denotativamente. Para poder desarrollar el análisis de la narrativa es necesario prestar atención a los "existentes" que según Casetti y Di Chio (2017: 155) "[...] comprenden todo aquello que se da y se presenta en el interior de la historia: seres humanos, animales, paisajes naturales, construcciones, objetos, etc.".

En primer lugar, dentro de la categoría de existentes se ha estudiado a los personajes. Como se mencionaba al inicio de este epígrafe, la cabecera de Isabel responde a un uso connotativo de la imagen, es probable que derivado de este hecho no aparecen imágenes de los personajes que protagonizan la serie. Sin embargo, esto no implica que no estén representados, al menos la protagonista del relato. La reina de Castilla se muestra reencarnada en un águila que durante el opening recorre, como Isabel, su camino hasta llegar y posarse en el trono.

El águila además es un símbolo o motivo heráldico utilizado comúnmente en la configuración de muchos escudos y blasones. Un animal que representa la fuerza y el poder de una manera elegante e impertérrita, que controla de forma omnipresente desde las alturas la tierra que habita. Una metáfora que encaja a la perfección con la figura protagonista de la serie, la reina. Aludiendo a los aspectos interiores que se apuntaban con anterioridad que venían expuestos gracias a los planos detalle, el águila participa de ellos, incluso llegando a transmutarse con una corona. 
Victor Ros, mucho más clásica a la hora de presentar a los personajes utiliza esas imágenes que simulan fotografías de la época ya mencionadas para tal fin. En la sucesión de planos van mostrando a los personajes tanto protagonistas como secundarios en situaciones cotidianas. La primera fotografía que abre la secuencia, recoge a Víctor Ros inmortalizado mientras dispara. El espacio entre personajes principales y secundarios en algunos casos es compartido, por lo que no se establece una jerarquía como ocurría en composiciones más clásicas donde se buscaba promocionar la participación de determinados actores. Esta cabecera, es la única de las tres que representa una relación total con los actantes de la serie, que no con los actores, tal y como se aprecia en la imagen 3.

Imagen 3. Fotogramas del opening de Victor Ros.
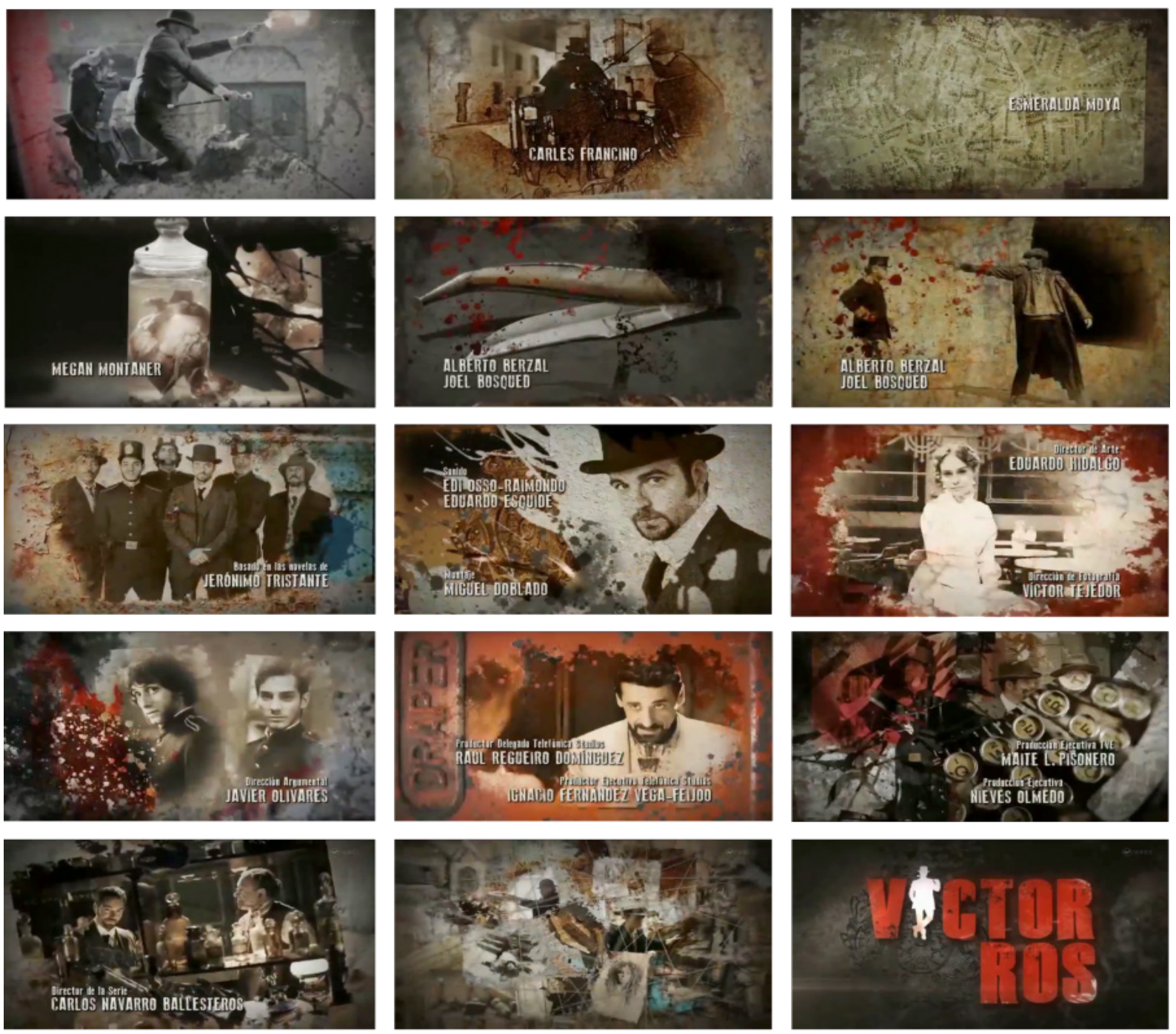

Fuente: RTVE. Elaboración propia.

El Ministerio del tiempo se enmarca en una situación intermedia entre sus iguales; por un lado, utiliza sombras o siluetas que no muestran a los personajes propiamente dichos, pero, por otro lado, mantiene esa conexión visible que las vincula con los actantes del relato puesto que presentan rasgos característicos de los mismos. Ejemplos de esto último serían la vestimenta de la figura masculina que baja las escaleras y que se acerca bastante a Julián, personaje que encarna Rodolfo Sancho o el vestido de época de la silueta femenina que mucho tiene que ver con el personaje interpretado por Aura Garrido. 
Una variable común a los tres genéricos es la ausencia de identificación entre actor y actante. Los rótulos con los nombres de los actores no guardan relación con los personajes a los que representan, es decir no comparten espacio y no conectan el mundo real con el universo de ficción. En el caso de Isabel porque ni siquiera se utilizan rótulos en la cabecera, lo que hace patente la intención de eliminar toda huella de irrealidad.

$\mathrm{Al}$ analizar los ambientes utilizados igualmente se trasluce una supeditación a la narrativa. En la misma línea que con los personajes, Isabel destaca por la utilización de espacios abstractos, pero no vacíos de sentido. Sería imposible ubicar y reconocer los paisajes que sobrevuela el águila de forma fehaciente en un mapa y que, no obstante, representan los campos de Castilla tan cercanos a la figura de la reina.

El Ministerio del tiempo de nuevo navega entre el exterior y el interior, acompañando a la silueta partiendo de la cotidianeidad cosmopolita y adentrándose en lo desconocido. Lugares que para el espectador prístino irán cobrando sentido una vez se produzca la inmersión en la trama. No se ha de olvidar la presencia de objetos relevantes que vertebran la esencia de la serie como son las puertas, las llaves y los relojes.

Si Víctor Ros no destaca por el aprovechamiento de los ambientes en cuanto a mostrar o ubicar espacios con relación al contenido principal - tan solo se puede poner énfasis en el plano final antes del título donde se ve representada la ciudad de Madrid—, sí deja claro el tiempo de la historia. El virado en sepia, las vestimentas de los personajes o los objetos de época insertados, determinan que temporalmente se sitúa en la etapa histórica contemporánea.

Una disposición temporal apenas perceptible pero presente en Isabel que, siguiendo en su coherencia minimalista, solo hace evidenciar el pasado en el trono y el manto que aparecen junto al título de la serie. Para finalizar con los aspectos narrativos, El Ministerio del tiempo vuelve a realzar la ligazón entre presente y pasado, un ir y venir por épocas y lugares; salidas y entradas por puertas que adelantan y atrasan relojes.

\subsection{Análisis de los elementos textuales}

De entre todas las funciones que cumplen los créditos, tanto de cine como de televisión, la primigenia es la de informar; aportar información al espectador sobre el contenido audiovisual. Sin embargo, existen otras funciones relevantes que aguardan imperceptibles a simple vista. El diseño de los textos cumple una función cohesiva con el discurso visual pretendido. Tanto es así que McLean (1987: 54-55) afirma que "[...] el rotulado puede ayudar a expresar un sentimiento o un estado de ánimo que armonice con el significado de las palabras".

Al observar la cabecera de Isabel resulta relevante esa ausencia de rótulos durante la pieza. El único texto que presenta es el propio título de la serie, lo que demuestra la intención apuntada anteriormente de desconexión total entre el mundo real y el creado. Algo que contrasta con Víctor Ros o El Ministerio del tiempo, imagen 4.

Imagen 4. Logos de las series Isabel, Victor Ros y El Ministerio del tiempo
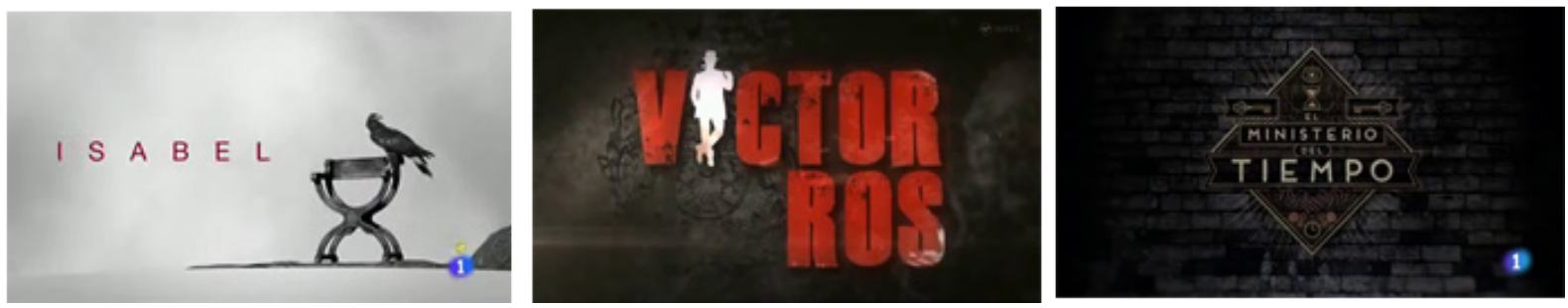

Fuente: RTVE. Elaboración propia. 
En ambos casos, utilizan colores neutros para los rótulos - Victor Ros emplea el blanco con matices de textura desgastada y El Ministerio del tiempo blanco y negro sólidos y uniformes-. Aparecen sucesivamente en diferentes ángulos periféricos de la pantalla y nunca se sobreponen a la acción principal que se desarrolla en el fondo. Los nombres propios siempre en letras mayúsculas y los cargos en minúsculas para los dos fragmentos. Se ha de destacar la presencia del nombre de la productora - Cliffhanger TV - tan solo en El Ministerio del tiempo, lo que denota una preocupación por la construcción de marca.

No obstante, todas presentan el rótulo con el nombre de la serie en los segundos finales y comparten categoría tipográfica, de palo seco. En Isabel se utiliza una tipografía grotesca en mayúsculas muy parecida a la Helvética, la Arial, la Univers o la Frutiger, todas basadas en la Akzidenz Grotesk. Dentro de las tipografías comprendidas en las de palo seco, de los siglos XIX y XX, son de las más elegantes. Para Víctor Ros se ha optado por una neogrotesca también en mayúsculas y El Ministerio del tiempo cuenta con una tipografía de diseño propio y en versales. A pesar de compartir características, el empleo de una u otra tipografía puede cambiar la percepción de lo que se transmite. Michelle Dougherty - directora creativa de Imaginary Forces - afirmaba en una entrevista realizada por Perkins (2016) que "A typeface is like an actor. Once you change the actor it's a different thing".

El título de Isabel está compuesto en una única línea que posee un trazo uniforme en cuanto al grosor, lo que la hace limpia y sin connotaciones evidentes. Mientras que en Victor Ros se opta por un título en dos líneas con un trazo rotundo y pesado que muestra cierto estrechamiento. Apenas deja espacio en el interior de las letras y permanece alineado a la derecha. Una elección de diseño que evoca contundencia - su tamaño supera el setenta por ciento de la pantalla-, como la demostrada por el protagonista en la resolución de los casos más sesudos, y vinculada directamente con éste al haber sido sustituida la 'i' por la figura de Víctor Ros.

Dentro del diseño minimalista de Isabel sobresale la exagerada separación entre letras, lo que se denomina interletrado o tracking, que en mayúsculas facilita la legibilidad y lectura del mensaje. Un rótulo que no supera en ningún caso el treinta por ciento de la pantalla, y que permanece ubicado prácticamente en el centro con respecto a la horizontal, pero en la mitad izquierda. Esta posición refuerza la legibilidad al respetar la dirección de lectura habitual en castellano. Una composición equilibrada al estar alineada con el águila posada sobre el trono.

Tanto Isabel como Víctor Ros se sirven del color rojo en su título, pero por razones muy diferentes. En Victor Ros las letras parten del fondo de la ciudad de Madrid, pasan por el blanco y van rellenándose con rojo - a excepción de la figura de Víctor Ros-, siguiendo la tónica de la cabecera en la que aparecen manchas y salpicaduras de tinta o sangre.

El rojo es un color "saliente" como lo denomina Castillo (2016) lo que hace que avance hacia el espectador atrayendo su atención, motivo por el que se puede utilizar en Isabel para destacar sobre el fondo duotono, conectando con los últimos fotogramas antes del rótulo y con la audiencia.

Finalmente, en El Ministerio del Tiempo la tipografía se organiza en forma de pie de lámpara en un bloque de cuatro líneas de composición, al centro, que ve cómo aumenta el cuerpo a medida que se lee. Y que forma un todo inserto en una geometría romboidal con diferentes símbolos esotéricos donde dominan las llaves como significado connotativo de su valor para abrir puertas. También se puede apreciar la existencia de relojes, de nuevo enfatizando la línea argumental de la serie. Como apunte final, se ha de destacar el color sólido de la fuente y del conjunto, blancos y dorados, con destellos que remarcan ese ocultismo que envuelve al secreto ministerio. 


\section{4. Análisis de sonido}

El sonido es el elemento compositivo más velado para la atención del espectador, al menos a priori. En este sentido ya advertían de su capacidad transmisiva, pero a la par escurridiza, Bordwell y Thompson (1995: 292) afirmando que "[...] puede conseguir efectos muy fuertes y aun así pasar bastante inadvertido". Las posibilidades narrativas del sonido son incuestionables y las opciones en su aplicación múltiples. En los openings analizados el sonido está presente a través de la música principalmente, aunque en Víctor Ros además se hace uso de los efectos auditivos para potenciar las imágenes.

La banda sonora funciona como guía encargada de hilvanar los elementos visuales y darles continuidad para conseguir la unidad a partir de la fragmentación inherente al relato visual. Como recuerda Chion (1997: 202), "[...] la representación de un orden simbólico, creador, organizador, susceptible de actuar sobre el resto, organizándolo, conduciéndolo".

De la misma manera que sucedía con la parte visual, en la auditiva se ha optado por realizar composiciones ex profeso para las cabeceras. Composiciones musicales que no pertenecen al mundo diegético - a excepción de los efectos que enfatizan acciones en Víctor Ros, como los disparos o los cristales rotos. Incluso el tic tac de un reloj que simula el movimiento de uno estático- - Se descarta, por tanto, la tendencia en algunas series de utilizar canciones de artistas conocidos o versiones de las mismas, facilitando el reconocimiento y recuerdo del espectador.

La composición de Federico Jusid, Anima Mea, de Isabel está presente durante todo el fragmento. Un tema lírico que conecta nuevamente con la protagonista, una férrea devota, y con el latín, el idioma de las oraciones católicas de la época. Además, la letra guarda relación con la narración pues como el propio Frades (2012) explica "[...] tiene un doble sentido: lo que significa Castilla para Isabel (su alma, su familia... su vida) y lo que queremos mostrar de Isabel: Su Alma." Una obra contenida y espiritual, majestuosa y sobria, un símbolo que refleja fielmente la esencia misma de la reina. Esta relación viene a confirmar la idea establecida por Sedeño (2011) de que cada emoción, situación, tiempo o lugar tiene sus propios sonidos e instrumentos, ayudando a situar el contenido o la marca.

Tanto Víctor Ros como El Ministerio del tiempo excluyen la letra de su música. El estilo de Víctor Ros recuerda a la banda sonora de los créditos en las películas y series de su homólogo británico, Sherlock Holmes. Con un ritmo vivo ofrece un trazado para la edición de las imágenes mediante cuerdas y vientos con sonidos agudos y brillantes; una técnica muy utilizada en el montaje de videoclips donde el ritmo lo determina la música.

Por el contrario, en El Ministerio del tiempo se sienten los tonos más graves, una cadencia lenta y oscura que hace llegar al espectador esa atmósfera misteriosa de lo desconocido y oculto. Vuelve a estar presente el leitmotiv que marca el diseño sonoro de toda la serie y en cierto modo su identidad. Una melodía que sirve de base y se utiliza con distintos arreglos. El tono de llamada de los teléfonos móviles de los protagonistas es perfectamente reconocible en este sentido, y es un claro ejemplo de lo que Gértrudix (2003) define como "icófono musical" que hace las veces de símbolo o marca del contenido.

Como señalan De la Cuadra de Colmenares y Marcos Recio (2018), la música se convierte en el componente ideal para vehicular la relación con la marca de la serie, a través de un empoderamiento de su carácter simbólico.

\section{Conclusiones}

Una vez finalizado el estudio de los tres openings seleccionados como muestra, y como se ha venido observando a lo largo de la investigación, todos los elementos que conforman las cabeceras de 
televisión contribuyen a la encapsulación o condensación en estas pequeñas secuencias de las claves que vertebran las series a las que presentan.

Todas ellas comparten un mismo creador y, sin embargo, no por ello los tres openings muestran una imagen de sello personal propio. Por el contrario, presentan rasgos identitarios con el relato al que anteceden. De esta manera, al aislar los distintos ejes de trabajo para poder estudiarlos de forma unitaria, se pone de manifiesto cómo se interrelacionan hasta el punto de complementarse y dar como resultado una transmisión homogénea.

1. En relación con el primer objetivo específico, la decisión de utilizar un tamaño de plano u otro, así como la elección de una imagen realista o producida mediante la animación, por ejemplo, variará la visión de ese universo creado. En el caso de los tipos de plano, la atmósfera narrativa se volverá un lugar angosto, peligroso, apacible, violento y un sinfín más de combinaciones posibles.

La naturaleza de la imagen, por su parte, realza esa contextualización. Las tres cabeceras estudiadas trabajan con imágenes de naturaleza diversa entre ellas. Isabel presenta imagen real que busca la neutralidad aparente al tratarse de un relato basado en hechos históricos. En el caso de Víctor Ros, la imagen producida es real, pero se beneficia de efectos y recursos para fomentar su trama de época. Finalmente, El Ministerio del Tiempo introduce al espectador desde la cabecera en un mundo fantástico con puertas para viajar en el tiempo que se refleja mediante la imagen animada. Por tanto, es el género asociado al relato de cada ficción el que determina el aspecto formal para mantener la coherencia entre contenido y estética, y le proporciona una identidad propia.

2. Si la elección del tipo de plano predispone para el mensaje, los elementos narrativos, a los que se aluden en el segundo objetivo, conectan con la historia. Cuando se muestran personajes y no actores se contribuye al reconocimiento y la empatía. Si, además, esos actantes se presentan en un contexto y con rasgos propios definitorios, ese vínculo con el relato aumenta, llegando a hacer difícil la disociación entre realidad y ficción.

Sin embargo, como se ha podido ver con el caso de Isabel, no siempre es imprescindible presentar a los personajes para que una cabecera muestre la finalidad de la serie, especialmente cuando se posee una imagen concreta dentro del imaginario colectivo que dista del referente en la ficción. Mediante la observación de los elementos narrativos se descarta la existencia de un patrón aplicable; por el contrario, son de nuevo, las características propias del relato las que influyen en la presentación de los personajes y el marco espacio-temporal.

3. En relación con el tercer objetivo planteado que pretende comprobar la utilización de los elementos textuales, se ha evidenciado cómo la tipografía contribuye a significar el contenido audiovisual mediante las convenciones culturales establecidas e interiorizadas socialmente. Esta práctica era recurrente en las películas de género - como el caso del western-, donde los aspectos connotativos destilados de cada tipo de letra ayudaban a clasificar desde el título, y de forma inequívoca, el género. Esta tendencia no se sigue en los openings analizados, en los que la selección de una fuente concreta no determina ninguna conexión notable con el universo de ficción. Además, en todas ellas se aprecia un uso desigual del texto en su función informativa sobre la serie.

4. De los cuatro ejes estudiados, es este último el que en todos los openings mantiene la unidad del resto de elementos, además de tener su propia función en la dotación de sentido. La creación de la banda sonora parte de su capacidad para crear identidad interna que completa la definición del relato, sin embargo, esa naturaleza interna se ve traspasada en muchas ocasiones y utilizada como una extensión de la imagen de marca que se proyecta de forma externa para el reconocimiento del espectador. No es difícil reconocer programas de televisión que se hicieron populares a través de sus sintonías; o películas conocidas por los temas principales de sus bandas sonoras. La banda sonora 
se convierte en una herramienta eficaz para mostrar brevemente la intención de la serie y crear una marca sólida que posibilite la ansiada pregnancia y el recuerdo. No caer en el olvido es un logro en tiempos donde prima lo efímero.

Las nuevas reglas establecidas en el consumo audiovisual obligan a las series a distinguirse y sobresalir de entre el creciente número de producciones anuales. El audiovisual ha pasado a convertirse en un activo más del ámbito mercantil en el que el espectador ha tomado conciencia de su poder de elección. De modo que las estrategias de marketing y promoción se configuran en torno a dos perspectivas, la creación de una identidad interna mediante los aspectos formales y narrativos y la construcción de una marca que proyecta una imagen externa del producto a la que contribuyen los elementos textuales y la banda sonora.

En definitiva, estos cuatro elementos confieren un valor intangible que se convierte en un activo de diferenciación frente a la homogeneidad de la oferta y que atiende a la constante necesidad de un sistema de creación de imagen de marca que diferencie entre una serie y otra a través de la transmisión de valores y emociones que generan un vínculo con el espectador.

\section{Bibliografía}

Aaker, D. A. (1996). Building Strong Brands. The Free Press.

Baraybar, A. (2006). Marketing en televisión. Madrid: Fragua.

Baraybar, A. y Luque de Marcos, J. (2018). Nuevas tendencias en la construcción de marcas: una aproximación al storydoing. Prisma Social (23), 435-458. https://revistaprismasocial.es/article/view/2745

Baxter, M. (2014). Notes on Cinemetric Data Analysis. http://cinemetrics.lv/articles.php

Bordwell, D. y Thompson, K. (1995). El arte cinematográfico: una introducción. Barcelona: Paidós Ibérica.

Bort, I. (2012). Nuevos paradigmas en los telones del relato audiovisual. contemporáneo: partículas narrativas de apertura y cierre en las series de televisión dramáticas norteamericanas. Tesis doctoral dirigida por Francisco Javier Gómez Tarín. Universitat Jaume I, Departament de Ciències de la Comunicació. https://www.tdx.cat/handle/10803/81927\#page=1

Brown, A. (1992). Autoedición. Texto y tipografía en la era de la edición electrónica. Madrid: ACK Publish.

Casetti, F. y Di Chio, F. (2017). Cómo analizar un film. 11ª edición. Barcelona: Paidós Comunicación.

Cascajosa, C. (2016). El ascenso de los 'showrunners': creación y prestigio crítico en la televisión contemporánea. index.comunicación, 6 (2), 23-40. https://journals.sfu.ca/indexcomunicacion/ index.php/indexcomunicacion/article/view/255/491

Castillo, J. M. (2016). Televisión, realización y lenguaje audiovisual. $3^{\mathrm{a}}$ edición. Madrid: Instituto Radio Televisión Española.

Costa, J. (2012). Construcción y gestión estratégica de la marca. Revista Luciérnaga. Facultad de Comunicación Audiovisual. Politécnico Colombiano Jaime Isaza Cadavid, año 4, edición 8, 20 25. https://revistas.elpoli.edu.co/index.php/luc/article/view/1487

Costa, J. (2005). Identidad televisiva en 4D. Bolivia: Editorial Design. 
Cuadrado, A. (2017). Narración audiovisual. Madrid: Síntesis.

De la Cuadra de Colmenares, E. y Marcos Recio, J. C. (2007, octubre). Cabeceras de series de ficción: símbolo y documento. Jornadas Internacionales de Jóvenes Investigadores en Comunicación. 14: La cultura y el entretenimiento en los medios de comunicación, Málaga. https://eprints.ucm.es/7072/1/Cabezas_de_series_de_ficcion.pdf

Frades, J. (2012, 24 de octubre). La cabecera de 'Isabel': la versión del director. RTVE. https:// www.rtve.es/television/20121024/cabecera-isabel-version-del-director/571496.shtml

Gamonal, R. (2013). Los títulos de crédito de series en la pequeña pantalla. En Rajas, M. y Álvarez, S. (Coord.) Tecnologías audiovisuales en la era digital, pp. 245-262. Madrid: Fragua.

Genette, G. (1997). Paratexts: Thresholds of Interpretation. Cambridge: Cambridge University Press.

Gértrudix, M. (2003). El icófono musical como portador publicitario. Icono 14 Revista de Comunicación y Nuevas Tecnologías, 1 (1). Iconos. https://icono14.net/ojs/index.php/icono14/ article/view/466. DOI https://doi.org/10.7195/ri14.v1i1.466

Hervás, C. (2002). El diseño gráfico en televisión: técnica, lenguaje y arte. Madrid: Cátedra.

Inceer, M. (2007). An Analysis of the Opening Credit Sequence in Film. CUREJ: College Undergraduate Reserch Electronic Journal, University of Pennsylvania. https://repository.upenn. edu/curej/65/

Labaig, F. (2007). Acerca de los títulos de crédito. Paperback, 4 - abril, 1-9. https://artediez.es/ paperback/wp-content/uploads/sites/13/2007/10/creditos.pdf

Matamala, Anna y Orero, Pilar (2011). Opening Credit Sequences: Audio Describing Films within Films. International Journal of Translation, 23 (2) (julio-diciembre). https://goo.gl/9GQt7b

McLean, R. (1987). Manual de Tipografia. Madrid: Hermann Blume Ediciones.

Millerson, G. (1991). Técnicas de realización y producción en televisión. Madrid: Instituto Oficial de Radio Televisión.

Ogilvy, D. (1983). Ogilvy y la publicidad. Barcelona: Ediciones Folio.

Pérez Rufí, J. P. y Jódar Marín, J. Á. (2018). Análisis de la edición, la postproducción y el diseño gráfico en el opening de la serie 'Narcos' (Netflix): propuesta de microanálisis fílmico para una secuencia de apertura para televisión. index.comunicación, 8 (1), 31-55. https://journals.sfu.ca/ indexcomunicacion/index.php/indexcomunicacion/article/view/348/343

Perkins, W. (2016, 9 de agosto). Stranger Things. Art of the Title. En https://www.artofthetitle. com/title/stranger-things/

Picarelli, E. (2013). Aspirational Paratext: The Case of 'Quality Openers' in TV Promotion. Frames Cinema Journal, 3. http://framescinemajournal.com/article/aspirational-paratexts-thecase-of-quality-openers-in-tv-promotion-2/

Poniewozik, J. (2015, 16 de diciembre). Streaming TV Isn't Just a New Way to Watch. It's a New Genre. The New York Times. En https://www.nytimes.com/2015/12/20/arts/television/streamingtv-isnt-just-a-new-way-to-watch-its-a-new-genre.html

Salt, B. (2006). Moving into Pictures. More on Film History, Stile, and Analysis. Londres: Starword. 
Sedeño, A. (2011). La música en los comerciales televisivos: el arma secreta. Sinfonía virtual, 18. http://www.sinfoniavirtual.com/revista/018/musica_comerciales_televisivos.php

Solana, G. y Boneu, A. (2007). Uncredited. Diseño gráfico y títulos de crédito. Barcelona: Index Books.

Williams, K. (2016). The Wonder Years: Nostalgia, Memory and Pastness in Television Credits. Alphaville: Journal of Film and Screen Media, Issue 12 (Winter), 59-77. http://www. alphavillejournal.com/Issue12/12_4Article_Williams.pdf

Zallo, R. (1992). El Mercado de la cultura. Estructura económica y política de la comunicación. Donostia: Tercera Prensa. 